\title{
Adult Height after Growth Hormone Treatment at Pubertal Onset in Short Adolescents Born Small for Gestational Age: Results from a Belgian Registry-Based Study
}

\author{
M. Thomas, ${ }^{1}$ D. Beckers, ${ }^{2}$ C. Brachet, ${ }^{3}$ H. Dotremont, ${ }^{4}$ M.-C. Lebrethon, ${ }^{5}$ P. Lysy $\left(\mathbb{D},{ }^{6}\right.$ G. Massa, ${ }^{7}$ \\ N. Reynaert, ${ }^{8}$ R. Rooman, ${ }^{1}$ S. van der Straaten, ${ }^{9}$ M. Roelants, ${ }^{10}$ and J. De Schepper $\mathbb{I D}^{11}$ \\ ${ }^{1}$ The Belgian Society for Pediatric Endocrinology and Diabetology (BESPEED), Bruxelles, Belgium \\ ${ }^{2}$ Division of Pediatric Endocrinology, Université catholique de Louvain, CHU UCL Namur, Yvoir, Belgium \\ ${ }^{3}$ Division of Pediatric Endocrinology, Hôpital Universitaire des Enfants Reine Fabiola (HUDERF), Bruxelles, Belgium \\ ${ }^{4}$ Division of Pediatric Endocrinology, UZ Antwerpen, Antwerpen, Belgium \\ ${ }^{5}$ Division of Pediatric Endocrinology, CHU-Notre-Dame des Bruyères, Chênée, Belgium \\ ${ }^{6}$ Division of Pediatric Endocrinology, Cliniques Universitaires Saint-Luc, Bruxelles, Belgium \\ ${ }^{7}$ Division of Pediatric Endocrinology, Jessa Ziekenhuis, Hasselt, Belgium \\ ${ }^{8}$ Division of Pediatric Endocrinology, UZ Leuven, Leuven, Belgium \\ ${ }^{9}$ Division of Pediatric Endocrinology, UZ Gent, Gent, Belgium \\ ${ }^{10}$ Department of Public Health and Primary Care, KU Leuven, Leuven, Belgium \\ ${ }^{11}$ Division of Pediatric Endocrinology, UZ Brussel, Brussel, Belgium
}

Correspondence should be addressed to J. De Schepper; jean.deschepper@uzbrussel.be

Received 19 October 2017; Revised 17 January 2018; Accepted 6 February 2018; Published 3 April 2018

Academic Editor: Donatella Capalbo

Copyright (c) $2018 \mathrm{M}$. Thomas et al. This is an open access article distributed under the Creative Commons Attribution License, which permits unrestricted use, distribution, and reproduction in any medium, provided the original work is properly cited.

Objectives. Information on the efficacy of GH treatment in short SGA children starting their treatment in adolescence is limited. Therefore, adult height (AH), total height gain, and pubertal height gain were evaluated in short SGA children who started GH treatment at pubertal onset. Patient and Methods. Growth data of 47 short SGA adolescents (22 boys) who started GH treatment at pubertal onset (PUB group) were compared with results from 27 short SGA patients (11 boys) who started GH therapy at least 1 year before pubertal onset (PrePUB group). Results. The PUB group achieved a mean $( \pm S D)$ total height gain of $0.8 \pm 0.7$ SDS and an AH of $-2.5 \pm 0.7$ SDS after $4.1 \pm 1.1$ years of GH treatment with a dosage of $41.8 \pm 8.4 \mu \mathrm{g} / \mathrm{kg} / \mathrm{day}$. These results were comparable with those in the PrePUB group, which was treated for a longer duration ( $5.8 \pm 2.1$ years), resulting in a total height gain of $1.1 \pm 0.7$ SDS and an AH of $-2.1 \pm 1.0$ SDS. Multiple regression analysis showed a significantly lower height gain in pubertal patients, females, and patients weighing less at start of $\mathrm{GH}$ treatment. An AH above -2 SDS and above the parent-specific lower limit of height was, respectively, reached in $28 \%$ and $70 \%$ of PUB and $44 \%$ and $67 \%$ of PrePUB patients (NS). AH SDS was positively correlated with the height SDS at start of GH. Conclusions. Short SGA adolescents starting GH therapy at an early pubertal stage have a modest and variable height gain. A normal AH can be expected in one third of the patients, especially in those with a smaller height deficit at onset of GH treatment.

\section{Introduction}

In Europe, growth hormone (GH) treatment is, since 2003, an approved growth-promoting therapy for children born small for gestational age (SGA) who do not show postnatal spontaneous catch-up growth. In Belgium, GH treatment is reimbursed since 2004 for short (<-2.5 SDS) SGA children, aged 4 years or older with a height $>1$ SDS below midparental height and without catch-up growth (height velocity $(\mathrm{HV})<0.0 \mathrm{SDS}$ ). Adult height $(\mathrm{AH})$ in short SGA children treated with GH is mainly dependent on the duration of treatment: the best response is obtained when treatment is 
started several years before the onset of puberty [1, 2]. Early diagnosis and referral for treatment of SGA children without catch-up growth before puberty has therefore been advocated [3].

Currently, median age at start of GH treatment in short SGA children in Belgium is 7.7 years (data on file, Belgian Society for Pediatric Endocrinology and Diabetology (BESPEED)). Despite efforts to promote early referral of short SGA children during the last decennium in most European countries, a variable percentage of short SGA children still consults for growth-promoting therapy around the onset of puberty (up to $17 \%$ in Belgium). Upper limits for chronological age or bone age for efficacious initiation of $\mathrm{GH}$ therapy have not been studied. Increasing the dose of GH and/ or additional treatment with GnRH agonists remain controversial issues in the management of short SGA adolescents, presenting with a major height deficit, and are not commonly performed in Belgium $[4,5]$.

To determine whether it is justified to start a GH treatment at early pubertal onset in short SGA adolescents, we retrospectively analysed our national GH registry. Pubertal height gain and $\mathrm{AH}$ were analysed in children who started $\mathrm{GH}$ around the onset of puberty and compared with the outcomes in short SGA children who initiated GH therapy at least one year before the onset of puberty. Efficacy of the treatment was measured by the following parameters: mean total height gain (in SDS), mean AH SDS and percentage of patients reaching an adult height $>-2$ SDS $(167.6 \mathrm{~cm}$ for boys and $154.7 \mathrm{~cm}$ for girls in Belgium), and mean AH SDS corrected for midparental height and percentage of patients reaching an $\mathrm{AH}$ above the parent-specific lower limit of height.

\section{Patients and Methods}

2.1. Patients. Growth data of GH-treated short SGA children were retrieved from the Belgian registry of $\mathrm{GH}$ treated children (BELGROW). This registry collects coded data since 1985 and was approved by the Ethical Committees of the participating centres of the BESPEED members. Informed consent was secured prior to entry of data in the registry.

Inclusion criteria were as follows: (1) diagnosis of SGA (Birth weight and/or length $<-2$ SDS), (2) treatment with recombinant human $\mathrm{GH}(\mathrm{rGH})$, given continuously on a daily basis during at least 3 years when treatment started before puberty and at least 2 years when started near the onset of puberty, (3) breast stage $<$ B3 for girls and a testicular volume $<10 \mathrm{ml}$ for boys at the start of $\mathrm{GH}$ therapy, and (4) achievement of $\mathrm{AH}$, defined as a height velocity $<2 \mathrm{~cm} /$ year. Exclusion criteria were as follows: (1) patients with a known syndrome (including Silver-Russell syndrome) and/or having major malformations and (2) treatment with $\mathrm{GnRH}$ agonist or other $\mathrm{GH}$-promoting agents, such as oxandrolone or letrozole.

In total, 196 short SGA patients treated since 1988 with a daily regimen of $\mathrm{rGH}$, no documented syndrome or major malformations, aged more than 16 years (girls) and 18 years (boys) by the end of 2012, and who stopped GH therapy were

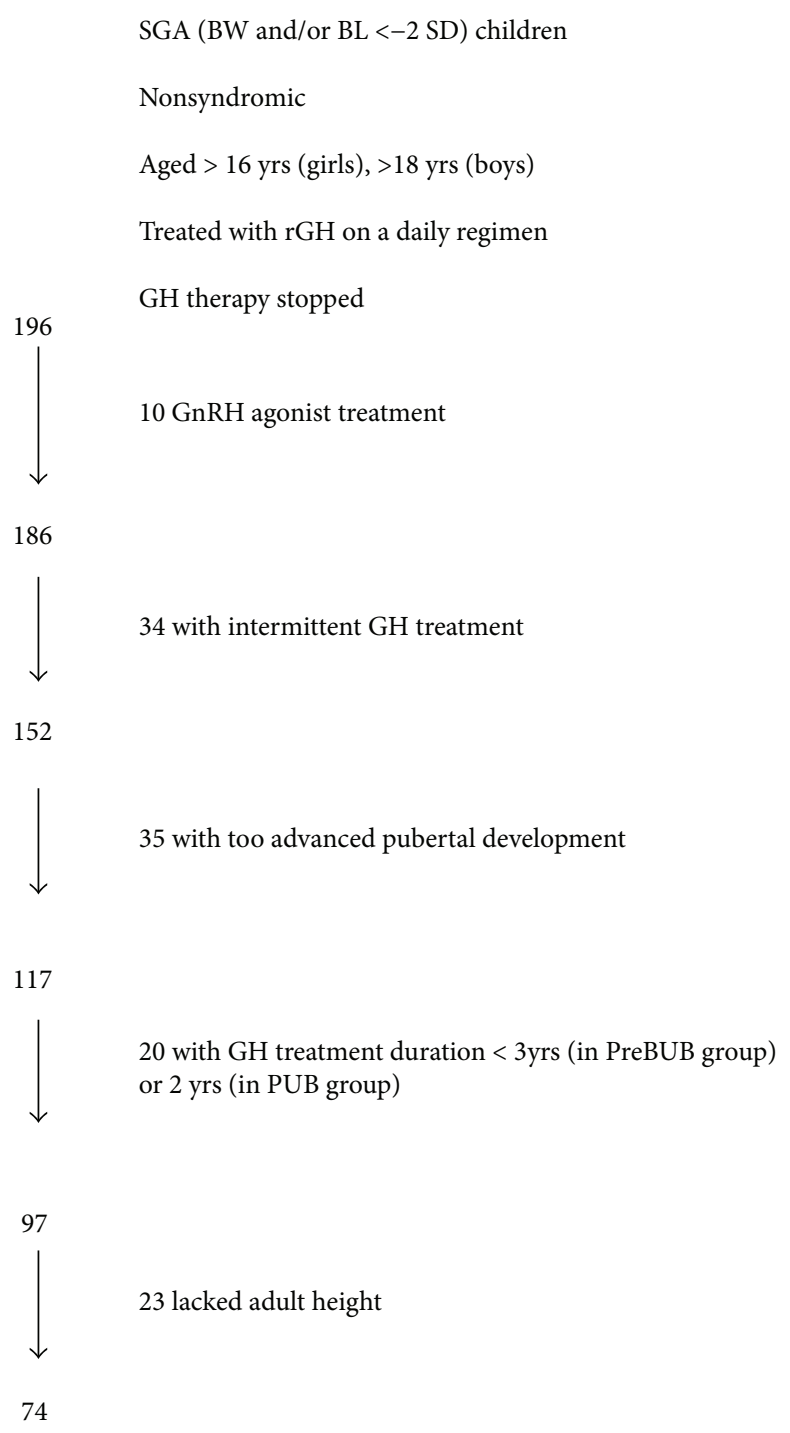

FIgURE 1: Patients selection flowchart.

retrieved from BELGROW (Figure 1). Ten patients treated with $\mathrm{GnRH}$ agonists were excluded, and data of 34 patients were not analysed because of intermittent $\mathrm{GH}$ treatment. Out of the 152 remaining patients, 35 had a too advanced pubertal development to be included. Twenty additional patients were excluded because the treatment duration was less than 3 years when prepubertal at the start of treatment or less than 2 years when pubertal at the start of treatment. For 74 (76\%) of the 97 remaining patients, an $\mathrm{AH}(\mathrm{HV}<2 \mathrm{~cm} /$ year $)$ was documented in the registry $(n=61)$ or obtained from the family doctor $(n=13)$. Birth and auxological characteristics at onset of $\mathrm{GH}$ treatment were comparable in patients with and without data on AH (data not shown).

The 74 included patients were divided into 2 groups according to their degree of pubertal maturation at start of $\mathrm{GH}$ treatment and/or during the first year of $\mathrm{GH}$ therapy: 27 patients (11 boys) started GH at least 1 year before the onset of puberty (PrePUB group) and 47 patients ( 22 boys) either started $\mathrm{GH}$ when they were already in puberty (at an 
TABle 1: Comparison of birth and parental auxological data between the PrePUB and PUB groups.

\begin{tabular}{lcccc}
\hline & $n$ & PrePUB group $(n=27)$ & PUB group $(n=47)$ & Significance \\
\hline Boys/girls, $n$ & 74 & $11 / 16$ & $22 / 25$ & $p=0.61$ \\
Birth weight, SDS & 73 & $-2.5 \pm 1.0$ & $-2.5 \pm 0.8$ & $p=0.78$ \\
Birth length, SDS & 71 & $-3.0 \pm 0.9$ & $-2.6 \pm 0.8$ & $p=0.12$ \\
Father's height, SDS & 67 & $-1.3 \pm 1.1$ & $-1.7 \pm 1.0$ & $p=0.14$ \\
Mother's height, SDS & 67 & $-1.2 \pm 1.1$ & $-1.5 \pm 1.2$ & $p=0.35$ \\
Midparental height, SDS & 67 & $-1.6 \pm 1.0$ & $-1.9 \pm 0.9$ & $p=0.10$ \\
\hline
\end{tabular}

early stage) $(n=28)$ or entered in puberty during the first year of treatment $(n=19)$ (PUB group).

2.2. Methods. At baseline and during follow-up visits every 3 to 6 months, the following data were collected: chronological age, height, body weight, pubertal stage, dose of $\mathrm{GH}$, and adverse events. Pubertal staging was determined according to Tanner and Whitehouse [6].

Anthropometric data (height, weight, and BMI) were expressed as z-scores adjusted for age and gender using the Flemish population references [7]. AH was defined as a height reached when growth velocity was $<2 \mathrm{~cm} /$ year. $A H$ SDS was calculated using adult references (SDS for age 21 years). Birth weight and length were expressed as z-scores adjusted for gestational age using the reference of Niklasson et al. [8]. The midparental height (MPH) SDS was calculated as (father's height SDS + mother's height SDS)/1.61 [9]. First year height velocity and gain in height SDS were calculated if measurements were available between 9 and 15 months after the start of GH therapy. Onset of puberty was defined by a testicular volume $\geq 4 \mathrm{ml}$ in boys and the presence of a breast stage 2 (B2) in girls. Pubertal height gain ( $\mathrm{cm}$ or SDS), defined by the AH ( $\mathrm{cm}$ or SDS) minus the height at onset of puberty ( $\mathrm{cm}$ or SDS), was calculated if a visit was available with pubertal development B2 in girls and testis volume $4 \mathrm{ml}$ in boys $(n=68)$. Total height gain was calculated as $\mathrm{AH}$ minus height at start of GH. The parent-specific lower limit of height SDS range was calculated as $(0.5 \times$ midparental height SDS) - 1.73 SDS [9]. Mean daily dosage ( $\mu \mathrm{g} / \mathrm{kg} /$ day) during the whole treatment period was calculated using the dosage recorded at each visit.

2.3. Statistical Analysis. Results are expressed as mean \pm SD. Both the percentage of subjects with an AH SDS $>-2$ and an AH SDS above the parent-specific lower limit was calculated. Continuous variables and percentages were compared across groups using unpaired $t$-tests, Mann-Whitney $U$ tests, or chi-square tests as appropriate. Multiple regression analysis with backward stepwise variable selection was used to analyse the relationship between characteristics of the patients and treatment parameters as independent variables and adult height SDS or total height gain SDS as the outcome. A $p$ value $<0.05$ was considered statistically significant. Stata 10.1 and IBM SPSS Statistics $21^{\circledR}$ were used for the statistical analysis.

\section{Results}

3.1. Auxological Characteristics (Table 1). Birth and parental auxological data were comparable in the PrePUB and PUB groups, as shown in Table 1. MPH SDS was in both groups significantly $(p<0.001)$ lower compared to the general population.

3.2. Growth Response, Adult Height, and Total Height Gain SDS (Table 2). At onset and at the end of GH treatment, height SDS was comparable in the PrePUB and PUB groups. The total height gain SDS $(1.1 \pm 0.7$ in the PrePUB versus 0.8 \pm 0.7 in the PUB group) was also similar after, respectively, $5.8 \pm 2.1$ and $4.1 \pm 1.1$ years of $\mathrm{GH}$ treatment $(p<0.001)$. There was no significant difference in duration of GH treatment between males and females in the PUB group, but males in the PrePUB group were treated longer (6.8 \pm 2.5 versus $5.1 \pm 1.3$ years $(p=0.03))$. A total height gain $>0.5$ SDS was observed in 85\% (23/27) of patients in the PrePUB group and in $64 \%(30 / 47)$ of patients in the PUB group $(p=0.06)$ (Figures 2(a) and 2(b)). Absolute $\mathrm{AH}$ was, respectively, $167.5 \pm 7.7$ in boys and $153.4 \pm 4.8 \mathrm{~cm}$ in girls in the PrePUB group and, respectively, $165.2 \pm 4.9$ and $150.8 \pm 4.4 \mathrm{~cm}$ in the PUB group. Whereas AH was above -2 SDS in $44.4 \%$ of the PrePUB group and in $27.7 \%$ of the PUB group $(p=N S)$, respectively, $66.7 \%$ and $69.8 \%$ reached an $\mathrm{AH}$ above their parent-specific lower limit $(p=\mathrm{NS})$.

3.3. Pubertal Growth (Table 3). Height SDS at start of puberty was significantly lower in the PUB group compared to the PrePUB group. In the PUB group, there was a gain of 0.6 \pm 0.7 in height SDS from onset of puberty until AH, while in the PrePUB group, height SDS increased by $0.2 \pm 0.9$ during this period. Total pubertal height gain in boys as well as girls was significantly higher in the PUB group than the PrePUB patients (resp., $28.2 \pm 5.3$ versus $23.2 \pm 3.3 \mathrm{~cm}$ in boys and $21.5 \pm 5.6$ versus $16.7 \pm 5.3 \mathrm{~cm}$ in girls).

3.4. Multivariate Analysis (Table 4). Multiple linear regression was used to determine the factors influencing the $\mathrm{AH}$ SDS and the total height gain. The following variables were included in the model: birth length and weight SDS, gender, target height SDS, height and weight SDS at start, mean total dosage $(\mu \mathrm{g} / \mathrm{kg} /$ day $)$, total duration of $\mathrm{GH}$ therapy, height gain SDS during the first year of GH therapy, and the group factor PrePUB or PUB. A significantly lower growth response and adult height outcome was observed in females in 


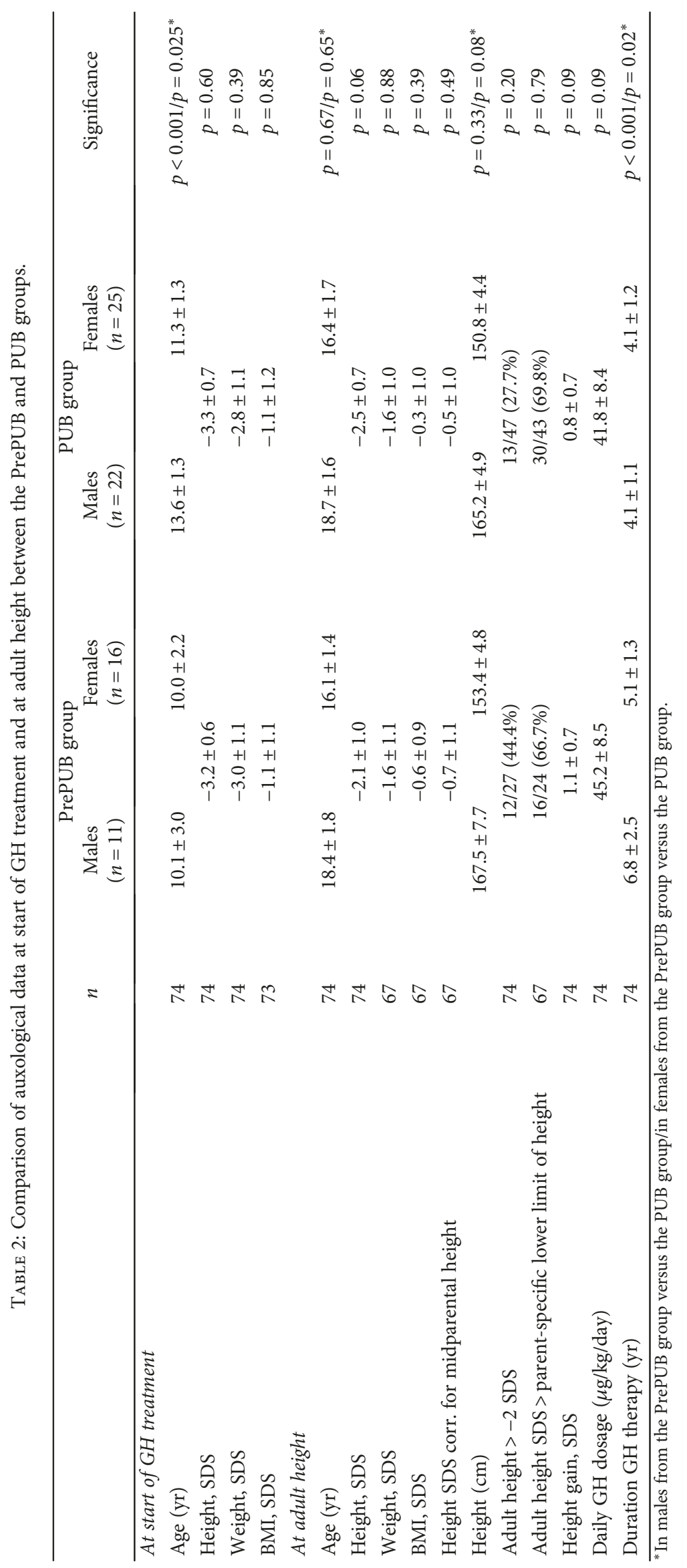




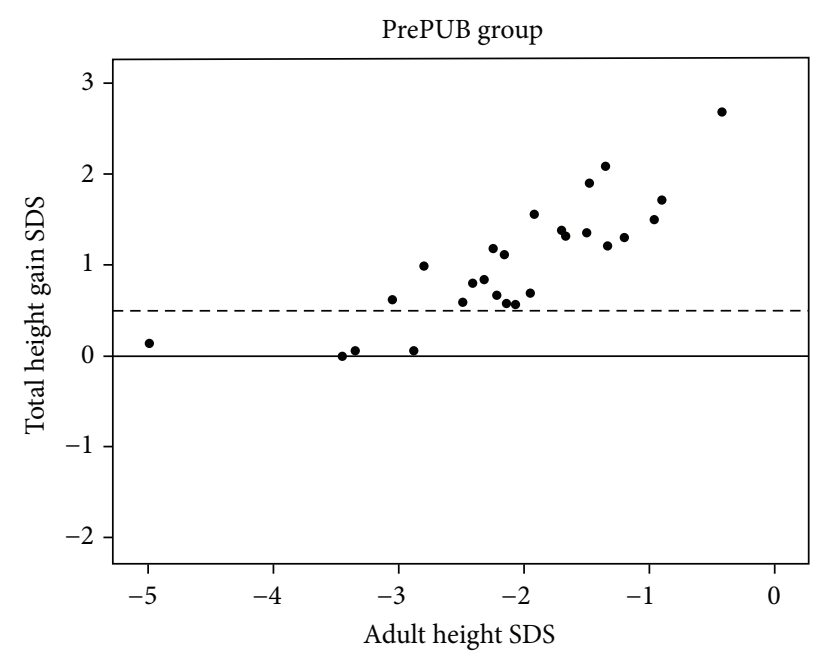

(a)

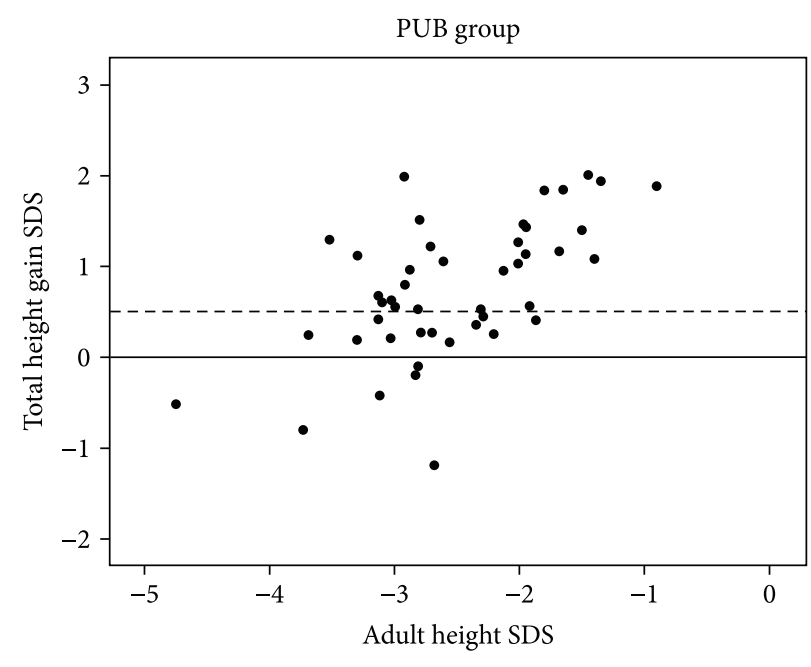

(b)

FIgURE 2: Scatterplot of total height gain SDS in relation to adult height SDS in the PrePUB group (a) and the PUB group (b).

TABle 3: Comparison of auxological data at onset of puberty and during puberty between the PrePUB and PUB groups.

\begin{tabular}{|c|c|c|c|c|c|c|c|c|}
\hline & \multirow[t]{2}{*}{$n$} & \multicolumn{3}{|c|}{ PrePUB group } & \multicolumn{3}{|c|}{ PUB group } & \multirow{2}{*}{ Significance } \\
\hline & & $n$ & Males $(n=11)$ & Females $(n=16)$ & $n$ & Males $(n=22)$ & Females $(n=25)$ & \\
\hline \multicolumn{9}{|c|}{$\begin{array}{l}\text { Height gain from start of GH until } \\
\text { pubertal onset }\end{array}$} \\
\hline Delta height, SDS & 53 & 26 & \multicolumn{2}{|c|}{$0.9 \pm 0.6$} & $27^{* *}$ & \multicolumn{2}{|c|}{$0.2 \pm 0.2$} & $p<0.001$ \\
\hline \multicolumn{9}{|c|}{ Data at start of puberty } \\
\hline Age (yr) & 68 & 26 & $13.4 \pm 1.3$ & $12.1 \pm 2.0$ & 42 & $13.4 \pm 1.1$ & $11.6 \pm 1.2$ & $p=0.98 / p=0.25^{*}$ \\
\hline Height, SDS & 68 & 26 & \multicolumn{2}{|c|}{$-2.3 \pm 0.6$} & 42 & \multicolumn{2}{|c|}{$-3.1 \pm 0.7$} & $p<0.001$ \\
\hline Weight, SDS & 68 & 26 & \multicolumn{2}{|c|}{$-2.2 \pm 1.0$} & 42 & \multicolumn{2}{|c|}{$-2.7 \pm 1.1$} & $p=0.04$ \\
\hline BMI, SDS & 68 & 26 & \multicolumn{2}{|c|}{$-1.0 \pm 0.9$} & 42 & \multicolumn{2}{|c|}{$-1.2 \pm 1.2$} & $p=0.68$ \\
\hline \multicolumn{9}{|c|}{$\begin{array}{l}\text { Height gain from onset of puberty } \\
\text { until AH }\end{array}$} \\
\hline Delta height, SDS & 68 & 26 & \multicolumn{2}{|c|}{$0.2 \pm 0.9$} & 42 & \multicolumn{2}{|c|}{$0.6 \pm 0.7$} & $p=0.056$ \\
\hline Delta height $(\mathrm{cm})$ & 68 & 26 & $23.2 \pm 3.3$ & $16.7 \pm 5.3$ & 42 & $28.2 \pm 5.3$ & $21.5 \pm 5.6$ & $p=0.01 / p=0.01^{*}$ \\
\hline
\end{tabular}

comparison with males, in patients lighter at start of $\mathrm{GH}$ treatment and in pubertal patients. AH SDS was positively correlated with the height SDS at start of GH.

\section{Discussion}

Our retrospective study showed that short SGA adolescents starting GH treatment just before (less than one year) the onset of puberty or at an early pubertal stage (around a mean age of 12.3 years) have a modest and variable height gain $(0.8$ \pm 0.7 SDS) when treated for 4 years at a mean dosage of $42 \mu \mathrm{g} / \mathrm{kg} /$ day. Only one third of them obtained a normal $\mathrm{AH}$, which was positively associated with height at start. On the other hand, GH-treated SGA adolescents reached an $\mathrm{AH}$ within parental target height range in a similar percentage as SGA children who were treated at least 1 year before the onset of puberty with a similar dosage but for longer duration (1.7 years longer). In addition, their pubertal height gain was greater than that of the prepubertal children starting GH treatment 2.3 years earlier. Our data suggest that when short SGA adolescents are requesting GH therapy and are responding to the reimbursement criteria, they should not be excluded from GH treatment because of their older age and imminent pubertal development, but a realistic growth prognosis should always be given.

The observed pubertal height gain in the SGA subjects starting GH treatment around puberty in our study was comparable with that observed in healthy British children, which is $29.5 \mathrm{~cm}$ in boys (testis volume $>3 \mathrm{ml}$ ) and $19.2 \mathrm{~cm}$ in girls (Tanner stage B2) [10]. In a Spanish study, 31 untreated short SGA children had a smaller pubertal height gain than reported in the national reference population [11]. In an Israeli study, a 
TABLE 4: Results of multiple linear regression analysis with adult height SDS and total height gain SDS as dependent variables (2 groups combined).

\begin{tabular}{lccccc}
\hline & \multicolumn{2}{c}{ Adult height } & \multicolumn{2}{c}{ Total height } \\
& \multicolumn{2}{c}{ SDS } & \multicolumn{2}{c}{ gain SDS } \\
& 0.97 & & \multicolumn{1}{c}{1.46} & $p$ \\
\hline Intercept & -0.33 & 0.042 & -0.34 & 0.04 \\
Gender (female) & 0.89 & $<0.001$ & - & \\
Height SDS at start & -0.18 & 0.040 & -0.21 & 0.006 \\
Weight SDS at start & -0.02 & 0.081 & -0.02 & 0.06 \\
Mean GH dosage $(\mu \mathrm{g} / \mathrm{kg} /$ day) & -0.35 & 0.042 & -0.33 & 0.05 \\
Group (pubertal) & 0.43 & & 0.21 & \\
$R^{2}$ & & & &
\end{tabular}

similar total pubertal growth and peak height velocity was observed in short SGA children $(n=76)$ in comparison with short children born appropriate for gestational age $(n=52)$. However, the earlier onset of puberty in SGA children was not taken into account in this particular study [12].

In our study, age at start of puberty was relatively late, in both boys and girls. We suspect that besides the exclusion of patients with additional GnRH treatment, a recruitment bias might be involved, as mainly short adolescents with a later onset of puberty, experiencing a more pronounced prepubertal growth deceleration, might have requested $\mathrm{GH}$ treatment. Without GH treatment, a rather low pubertal gain had to be expected. The GH treatment allowed the short SGA patients to present with a normal pubertal height gain as in normal growing non-SGA adolescents. In the prepubertal group, the observed pubertal height gain was comparable with the increments reported by Ranke and Lindberg in a group of 59 (24 females) short SGA children treated at least two years before puberty onset [13].

Studies evaluating adult height of short SGA children starting GH around pubertal onset are scarce. Carel et al. [14] treated with GH a cohort of 91 early pubertal SGA children at a mean age of 12.6 years for a relative short duration of $2.7 \pm 0.6$ years, at a relatively high dosage of $67 \mu \mathrm{g} / \mathrm{kg} /$ day. Many participants discontinued their treatment prematurely, before their height velocity was $<2 \mathrm{~cm} /$ year. Total height gain was $1.1 \pm 0.9$ SDS, making it possible for $47 \%$ of the treated SGA adolescents to achieve an adult height within the normal range for the general population ( $>-2$ SDS). Lem et al. [5] confirmed that SGA patients starting GH treatment during adolescence at a median age of 11.2 years (when $46 \%$ were already in puberty) at a dosage of either 33 or $66 \mu \mathrm{g} /$ $\mathrm{kg} /$ day still can have a significant catch-up growth. In 84 patients who attained $\mathrm{AH}$, height improved from -2.9 SDS at start of treatment to -1.7 SDS at AH (height gain around 1.2 SDS), permitting $62 \%$ of adolescents to attain an adult height above -2 SDS.

In our study, the almost similar growth outcome of SGA children treated around puberty with those starting some years before puberty might be partly explained by the relatively short duration of GH treatment in the prepubertal group, who started GH therapy at a relatively advanced age of 10.0 years. Studies reporting on the adult height and total height gain in prepubertal short SGA children after continuous $\mathrm{GH}$ therapy, but starting $\mathrm{GH}$ treatment at a much younger mean age than our cohort, have found better growth outcomes. Mean height gain was 1.4 SDS ( $n=162$; GH start around $7.8 \mathrm{yr}$ ) in the study of Ranke and Lindberg [2] and 1.7 SDS ( $n=73$; GH start at $7.7 \mathrm{yr})$ in the study of Bannink et al. [1]. We expect that within the following 5 years, more SGA patients who have started GH at a younger age will attain adult height and be available in our registry for a comparative adult height analysis. In addition, the study of quality of life outcome and employment status in relation to the age at start of treatment might be of interest in this cohort of SGA patients.

Given the wide variation in $\mathrm{GH}$-induced growth response in both prepubertal and pubertal subjects, predictors of the growth response and $\mathrm{AH}$ were evaluated. Like in other studies [2, 15, 16], AH was found to be positively related to the height SDS at start. In accordance with the findings of Dahlgren and Wikland [15] including prepubertal short SGA children, lighter SGA adolescents were found to experience better height gain in our study. We hypothesize that a lower adiposity at start of GH therapy in SGA children and especially in adolescents might induce a lesser degree of adrenal hyperandrogenism and/or compensatory hyperinsulinemia causing less bone age acceleration [17, 18]. In addition, the growth response and final height outcome to GH in our study was found to be gender dependent. The lower growth response in girls compared to boys in the PUB group was not explained by a difference in treatment duration, but may be related to the stronger influence of estrogens than androgens on bone maturation. Decreased as well as increased serum estradiol levels have been found in SGA children at completion of puberty [19]. Furthermore, SGA females, in comparison with males, might be at risk for a more pronounced adrenarche and/or insulin resistance, which are both associated with a more rapid bone maturation [20-22]. In our study, no effect of the $\mathrm{GH}$ dosage on $\mathrm{AH}$ outcome was found, but the dosage administered ranged only between 32 and $53 \mu \mathrm{g} / \mathrm{kg} /$ day for $90 \%$ of the population. Whereas in the prepubertal years a dose-dependent height gain has been found in most studies, this might be of less importance on the long term and in pubertal SGA children [15, 23-25].

Our study has several limitations. It was a retrospective study, without a control group on a relatively small number of patients. In retrospective studies and studies in whom a great proportion are lost to follow-up (for a quarter of the patients, no adult height was reported in our registry), some overestimation of the effect might be present. However, nonregistry studies have reported similar or even better growth effects in SGA adolescents [5, 14]. On the other hand, our approach to calculate AH SDS using adult references (SDS for age 21 years) may underestimate the AH SDS as some patients could have grown a few centimetres after the last visit available in the registry. The registry does not include untreated SGA children, making a direct comparison with untreated patients not possible. In untreated short SGA adolescents, a 0.5 SDS height increase from onset of puberty has been reported previously by Carel et al. [14] and should be 
taken into account. Retrieval of historical controls for comparison was judged difficult from the participating centres, since longitudinal data up to adult height are needed and the secular trend might favour a higher $\mathrm{AH}$ in the current GH-treated group.

To increase the efficacy of GH treatment in short SGA adolescents, several options have been tried or are still under investigation. Higher GH dosages have been studied in a recent trial by Lem et al. [5]. These authors showed that SGA patients starting their treatment around puberty and treated with a GH dosage of $66 \mu \mathrm{g} / \mathrm{kg} / \mathrm{day}$ obtained a $0.5-$ 0.6 SDS higher AH compared to those treated at $33 \mu \mathrm{g} / \mathrm{kg} /$ day, after correcting for influencing variables (gender, age at start, height SDS at start, treatment years before puberty, and target height SDS). However, the decision of treating SGA patients with higher GH doses must be weighed against potential long-term safety issues, given the risk of elevated serum IGF-1 levels in up to one third of the patients when GH dosages of $66 \mu \mathrm{g} / \mathrm{kg} /$ day are given [26]. Furthermore, the increase of GH dose is limited by the medication label for SGA.

The addition of GnRH agonists has been tested in short SGA adolescents in order to prolong GH treatment duration and improve adult height outcome [27]. There is however no convincing evidence that AH in short GH-treated SGA children can be improved by postponing pubertal onset with GnRH agonist. In a randomized study of short adolescents (Tanner stage 2 and 3), born either with appropriate Birth weight $(n=11)$ or SGA $(n=6)$ with a predicted adult height below -2 SDS and receiving GH in combination with a GnRH agonist for 3 years, no difference in adult height was observed in comparison with an age- and height-matched untreated control group $(n=15)$ [27]. Lem et al. [5] have shown that adding a GnRH agonist for 2 years in short GH-treated SGA children with a height at onset of puberty $<140 \mathrm{~cm}$ (considered as having a poor AH expectation) had a similar $\mathrm{AH}$ than patients receiving GH only. Prolonging the pubertal growth phase for a much longer period by $\mathrm{GnRH}$ agonist and/or the addition of estrogen blocking agents should be further explored, as GnRH agonist administration for 3.5 years was found to increase adult height by 0.6 SDS in a group of 26 adolescents with very short stature of different origins [28]. The psychosocial impact of such combined treatment (school performance, social acceptance, and general self-worth) should also be further investigated.

In conclusion, our study shows that short SGA adolescents starting GH therapy at an early pubertal stage have a modest and variable height gain. The best adult height outcome can be expected in those with the lowest height deficit at start of $\mathrm{GH}$ treatment. Our finding that female patients and those with a higher body weight are at higher risk for a poor adult height outcome needs confirmation in larger studies.

\section{Conflicts of Interest}

The authors declare that there is no conflict of interest regarding the publication of this paper.

\section{Acknowledgments}

The authors thank C. Derycke and F. Verlinde for their help in data collection. The authors would like to thank also the other members of BESPEED who contributed to the BELGROW registry (Belgian registry for patients treated with growth hormone): V. Beauloye, C. Brunelle, K. Casteels, M. Cools, M. Craen, K. De Waele, F. de Zegher, M. Den Brinker, A. France, I. Francois, I. Gies, J. Harvengt, C. Heinrichs, K. Logghe, M. Maes, T. Mouraux, A-S. Parent, S. Tenoutasse, S. Van Aken, J. Vanbesien, and R. Zeevaert.

\section{References}

[1] E. M. Bannink, D. J. van, P. G. Mulder, and A. C. HokkenKoelega, "Free/dissociable insulin-like growth factor (IGF)-I, not total IGF-I, correlates with growth response during growth hormone treatment in children born small for gestational age," The Journal of Clinical Endocrinology \& Metabolism, vol. 92, no. 8, pp. 2992-3000, 2007.

[2] M. B. Ranke and A. Lindberg, "Height at start, first-year growth response and cause of shortness at birth are major determinants of adult height outcomes of short children born small for gestational age and Silver-Russell syndrome treated with growth hormone: analysis of data from KIGS," Hormone Research in Paediatrics, vol. 74, no. 4, pp. 259-266, 2010.

[3] C. P. Houk and P. A. Lee, "Early diagnosis and treatment referral of children born small for gestational age without catch-up growth are critical for optimal growth outcomes," International Journal of Pediatric Endocrinology, vol. 2012, no. 1, 2012.

[4] P. E. Clayton, S. Cianfarani, P. Czernichow, G. Johannsson, R. Rapaport, and A. Rogol, "Management of the child born small for gestational age through to adulthood: a consensus statement of the International Societies of Pediatric Endocrinology and the Growth Hormone Research Society," The Journal of Clinical Endocrinology \& Metabolism, vol. 92, no. 3, pp. 804-810, 2007.

[5] A. J. Lem, D. C. van der Kaay, M. A. de Ridder et al., "Adult height in short children born SGA treated with growth hormone and gonadotropin releasing hormone analog: results of a randomized, dose-response GH trial," The Journal of Clinical Endocrinology \& Metabolism, vol. 97, no. 11, pp. 4096-4105, 2012.

[6] J. M. Tanner and R. H. Whitehouse, "Clinical longitudinal standards for height, weight, height velocity, weight velocity, and stages of puberty," Archives of Disease in Childhood, vol. 51, no. 3, pp. 170-179, 1976.

[7] M. Roelants, R. Hauspie, and K. Hoppenbrouwers, "References for growth and pubertal development from birth to 21 years in Flanders, Belgium," Annals of Human Biology, vol. 36, no. 6, pp. 680-694, 2009.

[8] A. Niklasson, A. Ericson, J. G. Fryer, J. Karlberg, C. Lawrence, and P. Karlberg, "An update of the Swedish reference standards for weight, length and head circumference at birth for given gestational age (1977-1981)," Acta Paediatrica Scandinavica, vol. 80, no. 8-9, pp. 756-762, 1991.

[9] M. B. Ranke, "Towards a consensus on the definition of idiopathic short stature," Hormone Research, vol. 45, no. 2, pp. 64-66, 1996. 
[10] D. D. Martin, R. C. Hauspie, and M. B. Ranke, “Total pubertal growth and markers of puberty onset in adolescents with GHD: comparison between mathematical growth analysis and pubertal staging methods," Hormone Research, vol. 63, no. 2, pp. 95-101, 2005.

[11] E. Vicens-Calvet, R. M. Espadero, and A. Carrascosa, "Longitudinal study of the pubertal growth spurt in children born small for gestational age without postnatal catch-up growth," Journal of Pediatric Endocrinology \& Metabolism, vol. 15, no. 4, pp. 381-388, 2002.

[12] L. Lazar, U. Pollak, O. Kalter-Leibovici, A. Pertzelan, and M. Phillip, "Pubertal course of persistently short children born small for gestational age (SGA) compared with idiopathic short children born appropriate for gestational age (AGA)," European Journal of Endocrinology, vol. 149, no. 5, pp. 425432, 2003.

[13] M. B. Ranke and A. Lindberg, "Prediction models for short children born small for gestational age (SGA) covering the total growth phase. Analyses based on data from KIGS (Pfizer International Growth Database)," BMC Medical Informatics and Decision Making, vol. 11, no. 1, p. 38, 2011.

[14] J. C. Carel, P. Chatelain, P. Rochiccioli, and J. L. Chaussain, "Improvement in adult height after growth hormone treatment in adolescents with short stature born small for gestational age: results of a randomized controlled study," The Journal of Clinical Endocrinology \& Metabolism, vol. 88, no. 4, pp. 1587-1593, 2003.

[15] J. Dahlgren and K. A. Wikland, "Final height in short children born small for gestational age treated with growth hormone," Pediatric Research, vol. 57, no. 2, pp. 216-222, 2005.

[16] M. A. de Ridder, T. Stijnen, and A. C. Hokken-Koelega, "Prediction model for adult height of small for gestational age children at the start of growth hormone treatment," The Journal of Clinical Endocrinology \& Metabolism, vol. 93, no. 2, pp. 477-483, 2008.

[17] O. Pinhas-Hamiel, D. Benary, K. Mazor-Aronovich et al., "Advanced bone age and hyperinsulinemia in overweight and obese children," Endocrine Practice, vol. 20, no. 1, pp. 62-67, 2014.

[18] J. H. Kwon, H. A. Lee, Y. J. Kim et al., "Effects of adrenal androgen levels on bone age advancement in prepubertal children: using the Ewha birth and growth cohort study," Journal of Korean Medical Science, vol. 32, no. 6, pp. 968-973, 2017.

[19] R. Verkauskiene, I. Petraitiene, and W. K. Albertsson, "Puberty in children born small for gestational age," Hormone Research in Paediatrics, vol. 80, no. 2, pp. 69-77, 2013.

[20] G. d'Annunzio, M. Vanelli, A. Pistorio et al., "Insulin resistance and secretion indexes in healthy Italian children and adolescents: a multicentre study," Acta Biomed, vol. 80, no. 1, pp. 21-28, 2009.

[21] H. Mellerio, C. Alberti, C. Druet et al., "Novel modeling of reference values of cardiovascular risk factors in children aged 7 to 20 years," Pediatrics, vol. 129, no. 4, pp. e1020-e1029, 2012.

[22] E. R. Faria, F. R. Faria, S. C. Franceschini et al., "Insulin resistance and components of metabolic syndrome, analysis by gender and stage of adolescence," Arquivos Brasileiros de Endocrinologia \& Metabologia, vol. 58, no. 6, pp. 610-618, 2014.

[23] Y. van Pareren, P. Mulder, M. Houdijk, M. Jansen, M. Reeser, and A. Hokken-Koelega, "Adult height after long-term, continuous growth hormone $(\mathrm{GH})$ treatment in short children born small for gestational age: results of a randomized, double-blind, dose-response GH trial," The Journal of Clinical Endocrinology \& Metabolism, vol. 88, no. 8, pp. 3584-3590, 2003.

[24] V. Boonstra, Y. van Pareren, P. Mulder, and A. HokkenKoelega, "Puberty in growth hormone-treated children born small for gestational age (SGA)," The Journal of Clinical Endocrinology \& Metabolism, vol. 88, no. 12, pp. 57535758, 2003.

[25] F. de Zegher and A. Hokken-Koelega, "Growth hormone therapy for children born small for gestational age: height gain is less dose dependent over the long term than over the short term," Pediatrics, vol. 115, no. 4, pp. e458-e462, 2005.

[26] J. C. Carel, E. Ecosse, F. Landier et al., "Long-term mortality after recombinant growth hormone treatment for isolated growth hormone deficiency or childhood short stature: preliminary report of the French SAGhE study," The Journal of Clinical Endocrinology \& Metabolism, vol. 97, no. 2, pp. 416425, 2012.

[27] S. A. van Gool, G. A. Kamp, B. H. Visser-van et al., "Final height outcome after three years of growth hormone and gonadotropin-releasing hormone agonist treatment in short adolescents with relatively early puberty," The Journal of Clinical Endocrinology \& Metabolism, vol. 92, no. 4, pp. 14021408, 2007.

[28] J. A. Yanovski, S. R. Rose, G. Municchi et al., "Treatment with a luteinizing hormone-releasing hormone agonist in adolescents with short stature," The New England Journal of Medicine, vol. 348, no. 10, pp. 908-917, 2003. 


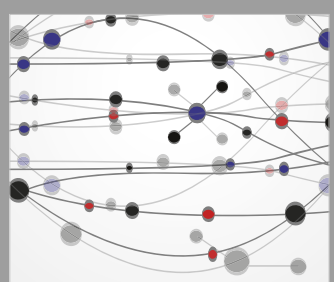

The Scientific World Journal
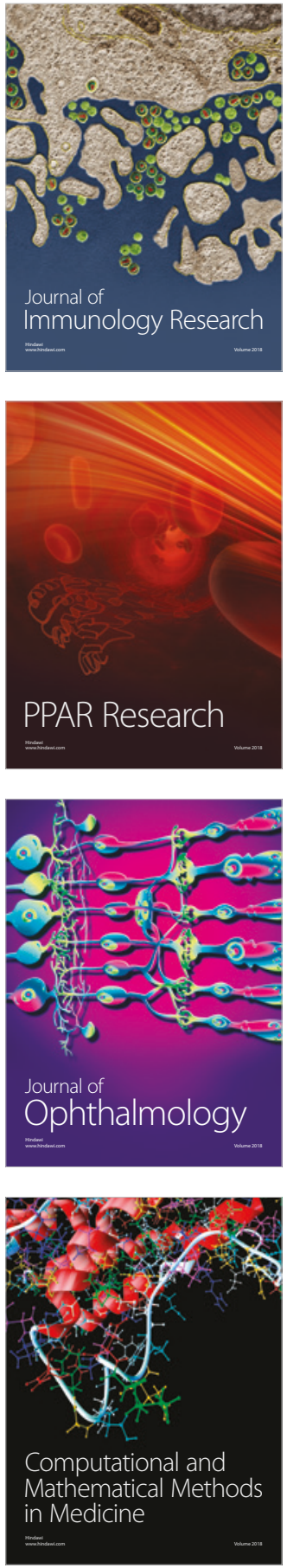

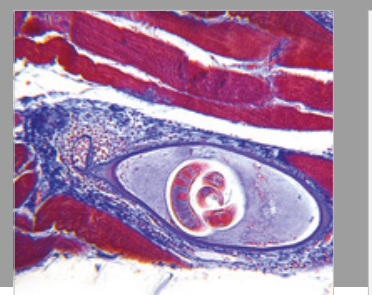

Gastroenterology Research and Practice

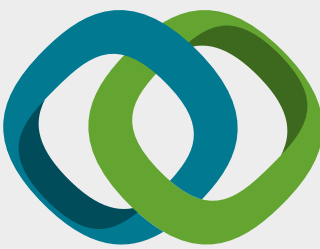

\section{Hindawi}

Submit your manuscripts at

www.hindawi.com


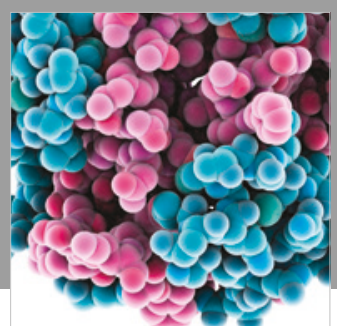

ournal of

Diabetes Research

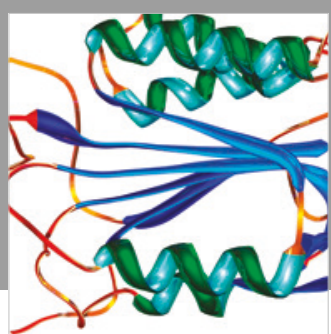

Disease Markers
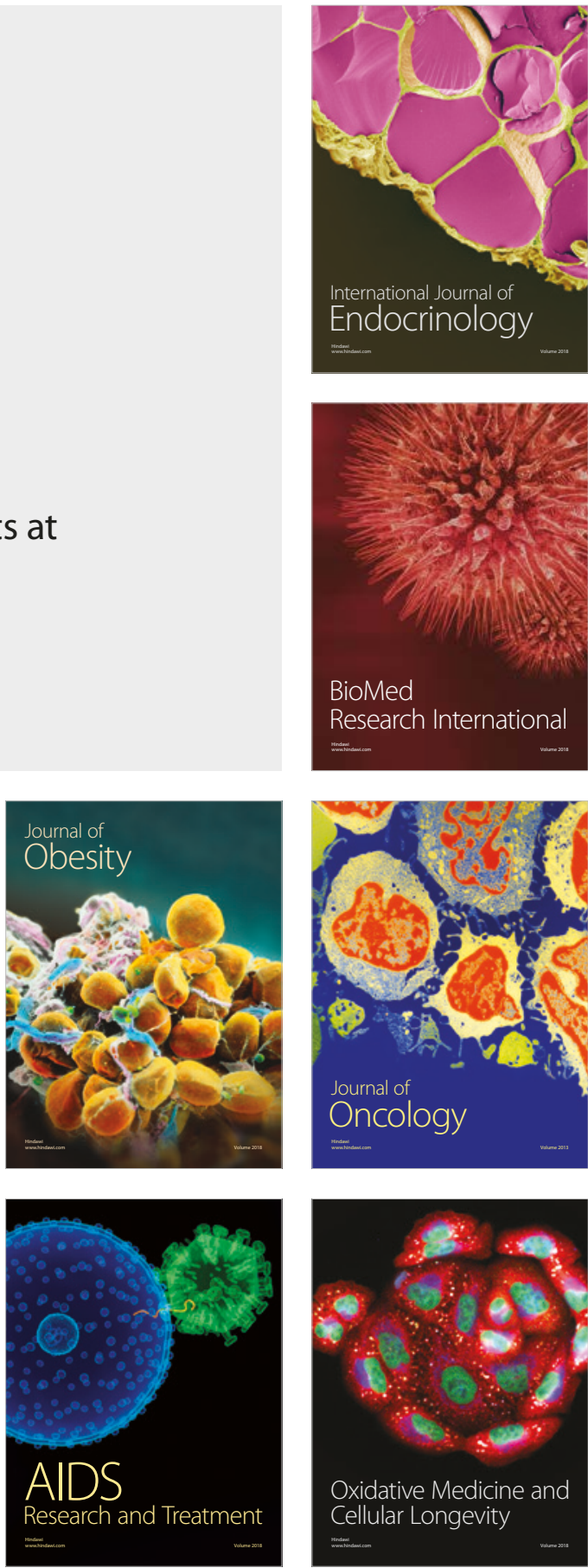